\title{
A new validated bio-analytical liquid chromatographic-tandem mass spectrometric (LC-MS/MS) method for the quantification of Azithromycin in human plasma
}

\author{
Kareem Mahmoud Younes a,* and Ehab Farouk El-Kady ${ }^{\mathrm{b}}$ \\ a Analytical Chemistry Department, Faculty of Pharmacy, Cairo University, Cairo, ET-11562, Egypt \\ b Pharmaceutical Chemistry Department, Faculty of Pharmacy, Cairo University, Cairo, ET-11562, Egypt \\ *Corresponding author at: Analytical Chemistry Department, Faculty of Pharmacy, Cairo University, Cairo, ET-11562, Egypt. \\ Tel.: +2.02.01141731229. Fax: +2.02.23628246. E-mail address: kareemchem99@yahoo.com (K.M. Younes).
}

\section{ARTICLE INFORMATION}

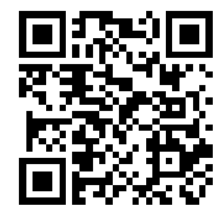

DOI: $10.5155 /$ eurjchem.5.2.241-246.1000

Received: 09 December 2013

Received in revised form: 26 December 2013

Accepted: 26 December 2013

Online: 30 June 2014

\section{KEYWORDS}

Azithromycin

Sildenafil citrate

Internal standard

Mass spectrometry

Liquid-liquid extraction

Liquid chromatography

\section{Introduction}

Azithromycin designated chemically as $2 R, 3 S, 4 R, 5 R, 8 R, 10 R$, $11 R, 12 S, 13 S, 14 R)$-2-ethyl-3,4,10-trihydroxy $3,5,6,8,10,12,14$ heptamethyl-15-oxo-11-\{[3,4,6-trideoxy-3-(dimethylamino)- $\beta$ $D$-xylo-]oxy\}-1-oxa-6-azacyclopentadec-13-yl2,6-dideoxy-3-C methyl-3-0-methyl- $\alpha$-L-ribo-hexopyranoside [1] (Figure 1) is a semi-synthetic macrolide antibiotic of the azalide class. Azithromycin inhibits bacterial protein synthesis by binding to the $50 \mathrm{~S}$ ribosomal subunit of the bacterial $70 \mathrm{~S}$ ribosome. It inhibits peptidyl transferase activity and interferes with amino acid translocation during the process of translation. Its effect may be bacteriostatic or bactericidal depending on the organism and the drug concentration. Its long half-life, which enables once daily dosing and shorter administration durations, is a property distinct from other macrolides. It is derived from erythromycin; however, it differs chemically from erythromycin in that a methyl-substituted nitrogen atom is incorporated into the lactone ring as shown in Figure 1.

Like erythromycin, it appears to bind to the same receptor, $50 \mathrm{~S}$ ribosomal subunits of susceptible bacteria and suppresses protein synthesis. It is used primarily to treat various bacterial infections, such as aerobic gram-positive microorganisms and aerobic gram-negative microorganisms. The incorporation of the nitrogen into the ring significantly alters the chemical, microbiologic and pharmacokinetic properties of AZI. It exhibits a more extensive spectrum of activity, greater acid stability and more favorable pharmacokinetic parameters than erythromycin [1].

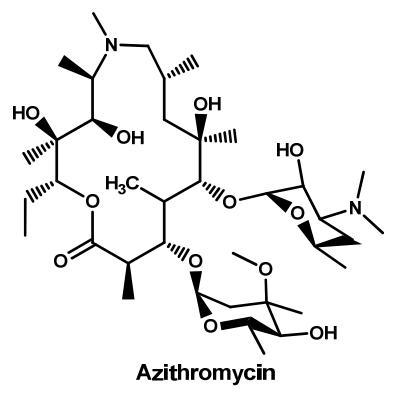

Figure 1. Chemical structure of azithromycin.

Several methods have been developed for determination of AZI in pharmaceutical dosage forms. These methods include 
high-performance liquid chromatography (HPLC) and microbiological methods.

Chromatographic separation is one of the essential and powerful components of the most quantitative analyses and HPLC is currently the most versatile tool which satisfies the needs for an optimum separation [2]. AZI has been analyzed by spectrophotometric methods [3-5], high-perfor-mance liquid chromatography using fluorescence [6-8], electro-chemical using amperometric detection [9-10] and coulometric detection [11-13] and mass spectrometry detector [14-17] for quantification in bulk material and pharmaceutical dosage forms. Fluorescence detection requires complicated sample pretreatment involving pre-column derivatization of the analyte. Assay procedures making use of electrochemical detection is often very time consuming, both in the sample preparation steps and the chromatography. The United States Pharmacopoeaia (USP) method [18] describes a high pH mobile phase $(\mathrm{pH}=11)$ as well as a specific column (Gamma alumina) which is quite expensive and difficult to obtain commercially as many of the column manufacturers do not supply this column. Also, the USP method employs amperometric electrochemical detection, which is not available in many laboratories. Therefore, there is a need for a convenient and effective method for determination of AZI in pharmaceutical dosage forms. Liquid chromatography with UV detection has been already employed for the analysis of AZI either in tablets [19] or in raw material [20] or in both [21]. Mass spectrometry methods may have the highest sensitivity, but the determination process is complex [22]. Various extraction methods have been reported for extraction of Azithromycin form plasma like, protein precipitation [23,24], pressurized liquid extraction (PLE) [25], liquid-liquid extraction [26,27] and solid phase extraction $[28,29]$.

The objective of the study was to develop simple, fast, sensitive, selective, accurate and economic method for quantification of Azithromycin in human plasma following liquid-liquid extraction by LC-MS/MS. Unlike other LC-MS methods, the presented method has the advantages of short run time (about $0.5 \mathrm{~min}$ ) which made it possible to analyze more than 400 plasma samples per day and a wide range of linearity $(5-1500 \mathrm{ng} / \mathrm{mL})$. Sildenafil citrate (Figure 2), designated chemically as 1-[[3-(6,7-dihydro-1-methyl-7-oxo-3propyl-1Hpyrazolo [4,3-d]pyrimidin-5-yl)-4-ethoxyphenyl] sulfonyl]-4-methylpiperazine citrate was used as internal standard (IS).
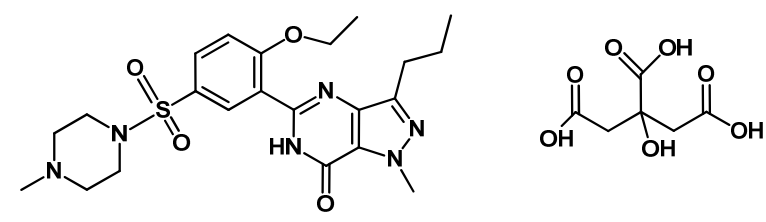

Figure 2. Chemical structure of sildenafil citrate (IS).

\section{Experimental}

\subsection{Chemicals and reagents}

Azithromycin reference standard (B.N: 1182090426; purity: $97.80 \%$ ) was obtained from CSPC, OUYI Pharmaceutical Co. Ltd (Shijiazhuang, China). Sildenafil citrate (B.N. 586032009SC; purity: 99.20\%) was employed as an internal standard (IS) obtained from BDR Pharmaceuticals International PVT. ITD (Mumbai, India). Water for HPLC was purchased from Merck, Germany. Formic acid and acetonitrile were of HPLC grade and purchased from Sigma-Aldrich Chemie Gmbh (Munich, Germany). Sodium carbonate and tert-butyl methyl ether were supplied by (Romil Ltd., London, UK). The control human plasma sample was procured from VACSERA (Cairo, Egypt).

\subsection{Equipment}

Acquity Ultra-Performance Liquid ChromatographicMS/MS (UPLC-MS/MS) system equipped with UPLC C18 (50 × 2.1, $5 \mu \mathrm{m}$ ) column, tandem mass triple-quadruple detector and electro spray ionization (ESI) probe was used for the assay (Waters, USA). The system included a vacuum degasser, a quaternary pump, a thermostatted auto-sampler and a column oven compartment. Data acquisition and data integration were done using Empower ${ }^{\text {TM }}$ Ver.2 Chromatography Data Software (CDS) solutions.

\subsection{Chromatographic conditions}

Separations were performed on UPLC C18 $(50 \times 2.1,5 \mu \mathrm{m})$ column. A mobile phase consisting of a mixture of acetonitrile$0.1 \%$ formic acid $(80: 20, v: v)$ was delivered at a flow rate of 0.5 $\mathrm{mL} / \mathrm{min}$ into the mass spectrometer. Aliquot of $7.5 \mu \mathrm{L}$ of the processed samples were injected into the column, which was kept at $30{ }^{\circ} \mathrm{C}$. Quantification was achieved with MS-MS detection in positive ion mode for both the internal standard and azithromycin using Waters ACQUITY TQD (triple quad detector) MS/MS (Foster City, CA, USA). The compound parameters viz. the collision energy (CE) and Cone voltage (CV) were 38 and 40 volt for azithromycin and 30 and 50 volt for sildenafil citrate. Detection of the ions was carried out in the multiple-reaction monitoring mode (MRM), by monitoring $\mathrm{m} / \mathrm{z}$ $749.62 / 82.87$ for azithromycin ion and $m / z$ 475.34/99.75 for sildenafil citrate ion (IS). Data acquisition and data integration were done using Empower ${ }^{\mathrm{TM}}$ Ver. 2 CDS software solutions.

\subsection{Preparation of stock solutions, secondary and working solutions}

\subsubsection{Stock solution of azithromycin for calibration and quality control}

A stock standard solution of azithromycin $(100 \mu \mathrm{g} / \mathrm{mL})$ was prepared by accurate weighing and transferring $10 \mathrm{mg}$ of azithromycin into a $100 \mathrm{~mL}$ volumetric flask and diluting to volume with the mobile Phase.

\subsubsection{Working solutions of azithromycin}

Different working standard solutions of azithromycin (B, C, D, E and F) were prepared by transferring $(10 \mathrm{~mL}, 1 \mathrm{~mL}, 100$ $\mu \mathrm{L}, 10 \mu \mathrm{L}$ and $1 \mu \mathrm{L}$, respectively) of stock solution each into a $100 \mathrm{~mL}$ volumetric flask and diluting to volume with mobile phase to give a final concentrations of $(10 \mu \mathrm{g} / \mathrm{mL}, 1 \mu \mathrm{g} / \mathrm{mL}, 100$ $\mathrm{ng} / \mathrm{mL}, 10 \mathrm{ng} / \mathrm{mL}$ and $1 \mathrm{ng} / \mathrm{mL}$, respectively).

\subsubsection{Stock solution of internal standard for calibration and quality control}

A stock standard solution of sildenafil citrate $(100 \mu \mathrm{g} / \mathrm{mL})$ was prepared by accurately weighing and transferring $10 \mathrm{mg}$ of sildenafil citrate into a $100 \mathrm{~mL}$ volumetric flask and diluting to volume with mobile phase.

\subsubsection{Working solution of internal standard}

A working standard solution of sildenafil citrate $(0.5$ $\mu \mathrm{g} / \mathrm{mL}$ ) was prepared by transferring $0.5 \mathrm{~mL}$ of stock solution into a $100 \mathrm{ml}$ volumetric flask and diluting to volume with mobile phase. Human plasma was chromatographed prior to use to determine possible interference with azithromycin or internal standard. 
Table 1. The optimum Multiple Reaction Mode parameters for both drug and IS.

\begin{tabular}{lllllll}
\multicolumn{1}{l}{ No } & Drug / IS & Precursor (Da) & Product (Da) & Dwell (sec) & Cone voltage (V) & Collision energy (V) \\
\hline 1 & Sildenafil (IS) & 475.34 & 99.75 & 0.100 & 50 & 30 \\
2 & Azithromycin & 749.62 & 82.87 & 0.100 & 40 & 38 \\
\hline
\end{tabular}

No significant interferences were observed in the lots of human plasma used for the preparation of calibration standards and quality control samples.

\subsection{Preparation of calibration curve and quality control solutions}

Standard curve was produced by preparing six plasma standards over the range of $5.0-1500.0 \mathrm{ng} / \mathrm{mL}$ for azithromycin. Standards were prepared in triplicates. Similarly, quality control (QC) samples were also prepared as a bulk based on an independent weighing of standard drug, at concentrations of 5.0 (Lower Limit of Quantitation, LLOQ), 10.0 (low; Low Quality Control, QCL), 400.0 (middle; Medium Quality Control, QCM) and $1200.0 \mathrm{ng} / \mathrm{mL}$ (high; High Quality Control, QCH) as a single batch at each concentration. Each calibrations or QC solution was prepared by spiking $50 \mu \mathrm{L}$ of the corresponding stock solution into $450 \mu \mathrm{L}$ of human plasma, then $100 \mu \mathrm{L}$ of $\mathrm{Na}_{2} \mathrm{CO}_{3}(30 \%, w: v)$ was spiked. Then extraction with $6 \mathrm{~mL}$ tert-butyl methyl ether was done. The mixture was vortexed for thirty seconds and centrifuged at $4000 \mathrm{rpm}$ for five minutes. The organic layer was then separated and evaporated in Epindorff evaporator then the residue was reconstituted with $250 \mu \mathrm{L}$ of IS dissolved in mobile phase and injected.

\subsection{Bio-analytical method validation}

The method was validated in accordance with international regulations [30]. The parameters determined were selectivity, specificity, matrix effect, linearity, precision, accuracy, recovery, stability and dilution integrity.

\section{Results and discussion}

\subsection{Method development}

\subsubsection{MS-MS tuning}

Mass parameters were tuned in both positive and negative ionization modes for the drug. Good response was found in positive ionization mode for both the drug and IS. The MRM state file parameters were optimized to maximize the response for both the drug and IS as shown in Table 1. The product ion mass spectrum of azithromycin and IS are presented in Figure 3.

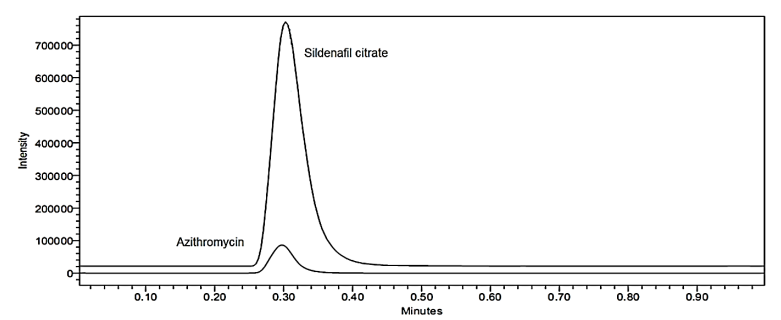

Figure 3. Mass spectrum of pure azithromycin and sildenafil citrate (IS).

\subsubsection{Chromatographic separation}

Separation was attempted using various combinations of acetonitrile and buffers with varying contents of each component on different columns like C8 and C18 of different types like Chromolith, Hypersil, Zorbax, Kromasil and Intertsil etc. Use of $0.1 \%$ formic acid helped in achieving good response for MS detection by facilitating ionization of the ions. A mobile phase consisting of acetonitrile and $0.1 \%$ formic acid $(80: 20$, $v: v$ ) was found suitable for both the drug and IS. The chromatographic separation was performed at room temperature on Waters C18 column (50 mm x $2.1 \mathrm{~mm}, 5 \mu \mathrm{m})$ which gave a good peak shape and response even at lower limit of quantitation level. A flow-rate of $0.5 \mathrm{~mL} / \mathrm{min}$ produced a good peak shape and permitted a runtime to $0.5 \mathrm{~min}$.

\subsubsection{Plasma sample extraction}

Different methods of sample extraction including protein precipitation with methanol or acetonitrile and liquid-liquid extraction (LLE) with different solvents commonly used were attempted. Better recoveries were obtained with LLE using tert-butyl methyl ether. Besides, LLE can be helpful in producing a spectroscopically clean sample and avoiding the introduction of nonvolatile materials onto the column and MS system and also minimized the experimental cost. Clean samples are essential for minimizing ion suppression and matrix effect in LC-MS/MS analyses. Tert-butyl methyl ether was found to be optimal, which can produce a clean chromatogram for a blank plasma sample and yield the highest recovery for the drug from the plasma.

\subsection{Method validation}

\subsubsection{Linearity}

Six calibration curves each consisting of a zero, non-zero and calibration standards prepared in human plasma were chromatographed. The concentrations of calibration standards cover the range $(5-1500 \mathrm{ng} / \mathrm{mL})$, the linearity was evaluated by calculating the linear regression (correlation coefficient, $r^{2}$ ), and by evaluating the back calculated concentrations of the calibration standards. The lower limit of quantification (LLOQ) of azithromycin is $(5 \mathrm{ng} / \mathrm{mL})$.

Calibration curves are found to be consistently accurate and precise over the calibration range of $5-1500 \mathrm{ng} / \mathrm{mL}$. The mean correlation coefficient $\left(r^{2}\right)$ is equal to 0.999 . Back calculations were made from the calibration curves to determine drug concentrations of each calibration standard. Data are presented in Table 2. A typical calibration curve is presented in Figure 4.

\subsubsection{Selectivity}

The selectivity of the method was examined by analyzing a blank human plasma extract and a blank plasma sample spiked with IS only (Figure 5). As shown in this figure, no significant interferences were observed in the lots of human plasma used for the preparation of calibration standards and quality control samples.

\subsection{3. $L L O Q$}

The lowest limit of reliable quantification for the drug was set at the concentration of the LLOQ which is the lowest quality control level with a coefficient of variation less than $20 \%$. LLOQ is $5 \mathrm{ng} / \mathrm{mL}$ with a signal to noise ratio of 6.1 . 
Table 2. Back-calculated standards from each calibration curve.

\begin{tabular}{|c|c|c|c|c|c|c|c|c|}
\hline \multirow[t]{2}{*}{ Calibration no } & \multicolumn{8}{|c|}{ Nominal concentrations $(\mathrm{ng} / \mathrm{mL})$} \\
\hline & 5 & 25 & 50 & 100 & 250 & 500 & 1000 & 1500 \\
\hline$\overline{1}$ & 5.414 & 24.873 & 49.112 & 111.359 & 256.809 & 513.472 & 1004.263 & 1558.137 \\
\hline 2 & 5.165 & 25.455 & 45.562 & 111.180 & 253.650 & 524.688 & 979.228 & 1513.784 \\
\hline 3 & 5.240 & 24.936 & 42.811 & 110.972 & 246.615 & 515.740 & 1004.699 & 1406.883 \\
\hline 4 & 6.054 & 22.758 & 42.811 & 104.843 & 240.341 & 507.540 & 981.047 & 1513.023 \\
\hline 5 & 5.868 & 24.936 & 42.811 & 110.999 & 246.615 & 515.740 & 1004.699 & 1554.451 \\
\hline 6 & 5.266 & 22.000 & 43.350 & 134.416 & 248.320 & 496.705 & 1004.699 & 1538.047 \\
\hline $\mathrm{N}$ & 6 & 6 & 6 & 6 & 6 & 6 & 6 & 6 \\
\hline Mean & 5.501 & 24.160 & 44.410 & 113.961 & 248.725 & 512.314 & 996.439 & 1514.054 \\
\hline $\operatorname{SD}( \pm)$ & 0.370 & 1.416 & 2.539 & 10.332 & 5.813 & 9.427 & 12.642 & 55.92411 \\
\hline CV $(\%)$ & 6.723 & 5.860 & 5.717 & 9.066 & 2.337 & 1.840 & 1.269 & 3.693667 \\
\hline$\%$ Nominal & 110.022 & 96.640 & 88.819 & 113.961 & 99.490 & 102.463 & 99.644 & 100.9369 \\
\hline
\end{tabular}

Table 3. Intra-day accuracy and precision.

\begin{tabular}{|c|c|c|c|c|c|c|}
\hline \multirow{2}{*}{$\begin{array}{l}\text { Run } \\
\text { number }\end{array}$} & \multicolumn{2}{|l|}{ QCL $10 \mathrm{ng} / \mathrm{mL}$} & \multicolumn{2}{|l|}{ QCM $400 \mathrm{ng} / \mathrm{mL}$} & \multicolumn{2}{|l|}{ QCH $1200 \mathrm{ng} / \mathrm{mL}$} \\
\hline & Conc. found (ng/mL) & $\%$ Nominal conc. & Conc. found (ng/mL) & \% Nominal conc. & Conc. found (ng/mL) & $\%$ Nominal conc. \\
\hline 1 & 11.23 & 112.3 & 384 & 96.00 & 1202 & 100.17 \\
\hline 2 & 10.24 & 102.36 & 399 & 99.75 & 1125 & 93.75 \\
\hline 3 & 9.63 & 96.32 & 374 & 93.50 & 1136 & 94.67 \\
\hline 4 & 9.32 & 93.21 & 386 & 96.50 & 1189 & 99.08 \\
\hline 5 & 9.75 & 97.45 & 401 & 100.25 & 1187 & 98.92 \\
\hline 6 & 8.52 & 85.21 & 422 & 105.50 & 1120 & 93.33 \\
\hline $\mathrm{N}$ & 6 & 6 & 6 & 6 & 6 & 6 \\
\hline Mean & 9.78 & 97.81 & 394.33 & 98.58 & 1159.83 & 96.65 \\
\hline $\mathrm{SD}( \pm)$ & 0.91 & & 16.86 & & 36.70 & \\
\hline CV (\%) & 9.29 & & 4.28 & & 3.16 & \\
\hline
\end{tabular}

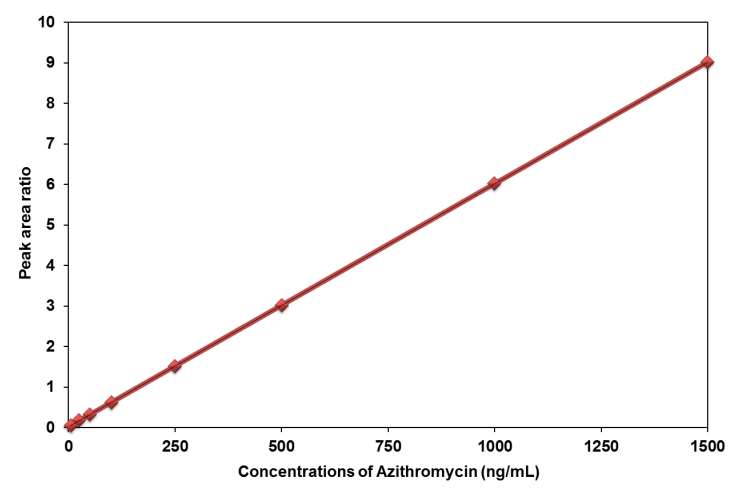

Figure 4. Standard Calibration curve of azithromycin in human plasma.

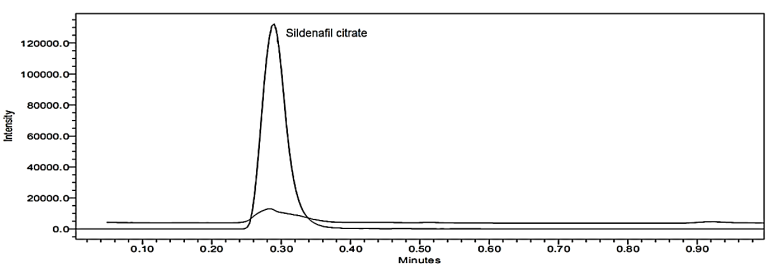

Figure 5. Mass spectrum of blank plasma compared to that containing only IS.

\subsubsection{Accuracy and precision}

\subsubsection{Intra-day accuracy and precision}

The intra-day accuracy and precision evaluations were assessed by repeated analysis of human plasma samples containing different concentrations of Azithromycin on separate occasions, same day. A single run consisted of a calibration curve plus 6 runs of low (QCL), medium (QCM) and high $(\mathrm{QCH})$ quality control samples, the intra-day coefficients of variation ranged between $9.29,4.28$ and $3.16 \%$. The intra-day percentages of nominal concentration ranged between 97.81, 98.58 and $96.65 \%$. Results are presented in Table 3.

\subsubsection{Inter-day accuracy and precision}

Inter-day accuracy and precision evaluations were performed by analyzing three sets of QCL, QCM and QCH quality control samples of Azithromycin in human plasma. One set was extracted and analyzed on one day (Day I). The other two sets were kept frozen, thawed, extracted and analysed on a next day (Day II) for the second set, and third day (Day III) for the last set.

The inter-day coefficients of variation ranged between $14.50,4.70$ and $3.40 \%$.

The inter-day percentages of nominal concentration ranged between 90.90, 97.30 and $98.90 \%$. Results are presented in Table 4.

\subsubsection{Extraction efficiency}

Recovery of Azithromycin was evaluated by comparing mean analyte responses of two processed samples of low (QCL), medium (QCM) and high (QCH) quality control samples to mean analyte responses of the same concentrations with spiked samples in previously extracted blank plasma. Mean recovery values are $89.08,97.02$ and $95.03 \%$ at low, medium and high quality control levels, respectively. Results are presented in Table 5.

\subsubsection{Dilution integrity}

Three replicates of the high quality control (QCH) were diluted five times in human plasma prior to sample processing and analysis. The calculated concentrations, including the dilution factor, yielded coefficients of variation of $4.48 \%$ for QCH. Percentages of nominal concentration are $100.67 \%$ Results are presented in Table 6.

\subsubsection{Stability studies}

\subsubsection{Post-preparative stability at $10^{\circ} \mathrm{C}$}

Samples prepared at low (QCL), medium (QCM) and high $(\mathrm{QCH})$ quality control levels were aliquoted and submitted to the sample processing procedure and kept at $10{ }^{\circ} \mathrm{C}$ (stability samples). 
Table 4. Inter-day accuracy and precision.

\begin{tabular}{|c|c|c|c|c|c|c|c|}
\hline \multirow[t]{2}{*}{ Day } & \multirow{2}{*}{$\begin{array}{l}\text { Run } \\
\text { number }\end{array}$} & \multicolumn{2}{|c|}{ QCL $10 \mathrm{ng} / \mathrm{mL}$} & \multicolumn{2}{|c|}{ QCM $400 \mathrm{ng} / \mathrm{mL}$} & \multicolumn{2}{|c|}{ QCH $1200 \mathrm{ng} / \mathrm{mL}$} \\
\hline & & $\begin{array}{l}\text { Conc. found } \\
\text { (ng/mL) }\end{array}$ & $\begin{array}{l}\% \text { Nominal } \\
\text { conc. }\end{array}$ & $\begin{array}{l}\text { Conc. found } \\
\text { (ng/mL) }\end{array}$ & $\begin{array}{l}\% \text { Nominal } \\
\text { conc. }\end{array}$ & $\begin{array}{l}\text { Conc. found } \\
\text { (ng/mL) }\end{array}$ & $\begin{array}{l}\% \text { Nominal } \\
\text { conc. }\end{array}$ \\
\hline \multirow[t]{6}{*}{$\mathrm{I}$} & 1 & 8.3 & 83.2 & 385.0 & 96.3 & 1203.0 & 100.3 \\
\hline & 2 & 8.4 & 84.0 & 386.0 & 96.5 & 1205.0 & 100.4 \\
\hline & 3 & 9.0 & 90.0 & 397.0 & 99.3 & 1220.0 & 101.7 \\
\hline & 4 & 10.0 & 100.0 & 375.0 & 93.8 & 1159.0 & 96.6 \\
\hline & 5 & 10.8 & 108.0 & 402.0 & 100.5 & 1156.0 & 96.3 \\
\hline & 6 & 11.3 & 113.0 & 406.0 & 101.5 & 1148.0 & 95.7 \\
\hline \multirow[t]{6}{*}{ II } & 1 & 10.4 & 103.6 & 410.0 & 102.5 & 1149.0 & 95.8 \\
\hline & 2 & 10.0 & 100.0 & 412.0 & 103.0 & 1157.0 & 96.4 \\
\hline & 3 & 11.2 & 112.0 & 416.0 & 104.0 & 1169.0 & 97.4 \\
\hline & 4 & 9.0 & 90.0 & 384.0 & 96.0 & 1158.0 & 96.5 \\
\hline & 5 & 7.0 & 70.0 & 365.0 & 91.3 & 1126.0 & 93.8 \\
\hline & 6 & 8.0 & 80.0 & 372.0 & 93.0 & 1136.0 & 94.7 \\
\hline \multirow[t]{6}{*}{ III } & 1 & 9.9 & 98.5 & 379.0 & 94.8 & 1187.0 & 98.9 \\
\hline & 2 & 8.5 & 85.0 & 377.0 & 94.3 & 1214.0 & 101.2 \\
\hline & 3 & 7.6 & 76.0 & 388.0 & 97.0 & 1256.0 & 104.7 \\
\hline & 4 & 7.4 & 74.0 & 397.0 & 99.3 & 1236.0 & 103.0 \\
\hline & 5 & 7.9 & 79.0 & 346.0 & 86.5 & 1245.0 & 103.8 \\
\hline & 6 & 8.9 & 89.0 & 406.0 & 101.5 & 1233.0 & 102.8 \\
\hline $\mathrm{N}$ & & 6.0 & 6.0 & 6.0 & 6.0 & 6.0 & 6.0 \\
\hline Mean & & 9.1 & 90.9 & 389.1 & 97.3 & 1186.5 & 98.9 \\
\hline $\mathrm{SD}( \pm)$ & & 1.3 & & 18.4 & & 40.7 & \\
\hline CV (\%) & & 14.5 & & 4.7 & & 3.4 & \\
\hline
\end{tabular}

Table 5. Recovery of azithromycin.

\begin{tabular}{|c|c|c|c|c|c|c|}
\hline \multirow[t]{2}{*}{ Analyte samples } & \multicolumn{3}{|c|}{ Theoretical true spiked in matrix analyte response } & \multicolumn{3}{|c|}{ Extracted sample analyte response } \\
\hline & Analyte 1 & Analyte 2 & Analyte 3 & Analyte 1 & Analyte 2 & Analyte 3 \\
\hline Sample 1 & 18562 & 987541 & 2854126 & 16598 & 945876 & 2854712 \\
\hline Sample 2 & 17451 & 965147 & 2963514 & 14856 & 952147 & 2685471 \\
\hline Sample 3 & 21365 & 996321 & 2745214 & 19657 & 963214 & 2596874 \\
\hline $\mathrm{N}$ & 3 & 3 & 3 & 3 & 3 & 3 \\
\hline Mean & 19126.00 & 983003 & 2854284.667 & 17037.00 & 953745.667 & 2712352.33 \\
\hline $\mathrm{SD}( \pm)$ & 2017.03 & 16074.81421 & 109150.0865 & 2430.42 & 8778.85883 & 131004.058 \\
\hline CV (\%) & 10.55 & 1.64 & 3.82 & 14.27 & 0.92 & 4.83 \\
\hline Concentration $(\mathrm{ng} / \mathrm{mL})$ & 10 & 400 & 1200 & 10 & 400 & 1200 \\
\hline Mean recovery (\%) & & & & 89.08 & 97.02 & 95.03 \\
\hline
\end{tabular}

Table 6. Results of dilution integrity.

\begin{tabular}{lll}
\hline Table 6. Results of dilution integrity. & Conc. vound (ng/mL) & \% Nominal concentration \\
\hline Analyte samples & 1156.00 & 96.33 \\
Sample 1 & 1204.00 & 100.33 \\
Sample 2 & 1264.00 & 105.33 \\
Sample 3 & 3 & 3 \\
\hline N & 1208.00 & 100.67 \\
Mean & 54.11 & \\
SD ( \pm CV $(\%)$ & 4.48 & \\
\hline
\end{tabular}

Three replicates of those quality control samples were freshly processed with a calibration curve and analyzed in a single run to serve as time zero (comparison samples). After 100 hours, a calibration curve was freshly processed and analyzed with all stability samples in a single run. Concentrations were calculated to determine \% change after 100 hours when compared to time zero. Azithromycin is found to be stable for 100 hours at $10^{\circ} \mathrm{C}$ following sample processing with \% changes of $-9.71,-7.40$ and $-2.68 \%$. Results are presented in Table 7.

\subsubsection{Short-term stability of azithromycin in matrix at room temperature}

Samples were prepared at low (QCL), medium (QCM) and high (QCH) quality control levels. Three replicates of low, medium and high quality control samples were left at room (stability samples). Three replicates of those quality controls samples were freshly processed with a calibration curve and, analyzed in a single run to serve as time zero (comparison samples). After 24 hours, a calibration curve was freshly processed and analyzed with all stability samples in a single run. Concentrations were calculated to determine \% change over the time when compared to time zero. Azithromycin is found to be stable in human plasma for 24 hours at room temperature with \% changes of $-9.34,-9.03$ and $-1.77 \%$. Results are presented in Table 7.

\subsubsection{Freeze and thaw stability at $-20^{\circ} \mathrm{C}$}

Samples were prepared at low (QCL), medium (QCM) and high (QCH) quality control levels, aliquoted and frozen at -20 ${ }^{\circ} \mathrm{C}$. Some of the aliquots of quality control samples were subjected to three freeze-thaw cycles (stability samples). A calibration curve and quality control samples were freshly prepared and processed with 3 replicates of stability samples and analysed in a single run. Azithromycin is found to be stable in human plasma after three freeze-thaw cycles at, $-20{ }^{\circ} \mathrm{C}$ with coefficients of variation of 7.78, 1.71 and $1.48 \%$ and nominal concentrations of 103.66, 95.75 and $95.61 \%$ for QCL, QCM and QCH, respectively. Results are presented in Table 7.

\subsubsection{Long-term stability of azithromycin in matrix at -20 ${ }^{\circ} \mathrm{C}$}

Stability samples were prepared in human plasma at low (QCL), medium (QCM) and high (QCH) quality control levels and stored at $-20^{\circ} \mathrm{C}$ (stability samples). 
Table 7. Summary of validation results.

Parameters
Canearity
Inter-day accuracy
Inter-day precision
Intra-day accuracy
Intra-day precision
Recovery of analyte
Lower limit of quantification
Dilution integrity accuracy
Dilution integrity precision
Post-preparative stability at $10{ }^{\circ} \mathrm{C}$
Short-term stability of analyte in matrix at $-20{ }^{\circ} \mathrm{C}$
Long-term stability of analyte in matrix at $-20{ }^{\circ} \mathrm{C}$
Freeze and thaw stability of analyte in matrix at -20 ${ }^{\circ} \mathrm{C}$
$\quad$ A calibration curve and 3 replicates of low and high quality
control samples (comparison samples) were freshly processed
with three replicates of stability samples and analysed in a
single run. Concentrations were calculated to determine $\%$
change over time. Azithromycin is found to be stable in human
plasma for 52 days at $-20{ }^{\circ} \mathrm{C}$ with $\%$ changes of $-11.12,-7.09$
and - $3.05 \%$. Results are presented in Table 7 .

\section{Conclusion}

The developed LC-MS/MS assay for azithromycin is rapid, selective, and suitable for routine measurement of subject samples. This study reports a high throughput liquid-liquid extraction method for extraction of azithromycin in human plasma using LC-MS/MS. The developed method provided a short run time of about 0.5 minutes that can afford the analysis of more than 400 plasma samples per day. The present method also provided excellent specificity and linearity with an LLOQ of $5 \mathrm{ng} / \mathrm{mL}$ for azithromycin.

\section{Acknowledgement}

The authors thank The Holding Company for Biological Products and Vaccines (VACSERA), Cairo, Egypt, for providing human plasma.

\section{References}

[1]. Reynolds, J. E. F. (Ed.), Martindale: The Extra Pharmacopoeia, $36^{\text {th }}$ edition, the Pharmaceutical Press, London, 2009, 207.

[2]. Ghodsi, R.; Kobarfard, K.; Tabatabai S. A. Iranian J. Pharm. Res. 2012, 11, 123-127.

[3]. Suhagia, B. N.; Shah, S. A.; Rathod, I. S.; Patel, H. M.; Doshi, K. R. Indian J. Pharm. Sci. 2006, 68, 242-245.

[4]. Mallah, M. A.; Sherazi, S. T. H.; Mahesar, S. A.; Rauf, A. Pak. J. Anal. Environ. Chem. 2011, 12, 61-67.

[5]. Khashaba, P.Y.J. Pharm. Biomed. Anal. 2002, 27, 923-932.

[6]. Sastre, T. J.; Guchelaar, H. J. J. Chromatogr B. 1998, 720, 89-97.

[7]. Bahrami, G.; Mirzae, S.; Kiani, A. J. Chromatogr B. 2005, 820, 277-281.

[8]. Bahrami, G.; Mohammadi, B. J. Chromatogr B. 2006, 830, 355-358.

[9]. Taninaka, C.; Ohtani, H.; Hanada, E.; Kotaki, H.; Sato, H.; Iga, T. J. Chromatogr B. 2000, 738, 405-411.

[10]. Palomeque, M. E.; Ortiz, P. I. Talanta 2007, 72, 101-105

[11]. Kees, F.; Spangler, S.; Wellenhofer, M. J. Chromatogr A. 1998, 812, 287 293.

[12]. Shepard, R. M.; Duthu, G. S.; Ferraina, R. A.; Mullins, M. A. J. Chromatogr. 1991, 565 (1-2), 321-337.

[13]. Gandhi, R.; Kaul, C. L.; Panchagnula, R. J. Pharmaceut. Biomed. Anal. 2000, 23, 1073-1078.

[14]. Fouda, G. H.; Schneider, R. P. Ther. Drug Monit. 1995, 17, 179-183.

[15]. Abuin, S. O.; Codony, R.; Ramon, N. O.; Granados, M. E.; Dolors, P. M. J. Chromatogr A. 2006, 1114(1), 73-81.

[16]. Koch, D. E.; Bhandari, A.; Close, L.; Robert, P. H. J. Chromatogr A. 2005, 1074, 17-22.

[17]. Shen, Y.; Yin, C.; Mengxiang, S. U.; Jiasheng, T. U. J. Pharmaceut. Biomed. Anal. 2010, 52, 99-104.

[18]. Rockville, M. D. U. S. Pharmacopeia 35, National Formulary 30. The United States Pharmacopeial Commission Inc. 2010, 1965-1973.

[19]. Miguel, L.; Barbas, C. J. Pharm. Biomed. Anal. 2003, 33, 211-217.
Value

$r \geq 0.999$

$5-1500 \mathrm{ng} / \mathrm{mL}$

QC \% nominal conc., $90.90,97.30$ and $98.90 \%$

QC coefficients of variation, $14.50,4.70$ and $3.40 \%$

QC \% nominal conc., 97.81, 98.58 and $96.65 \%$

QC coefficients of variation, $9.29,4.28$ and $3.16 \%$

QC means, 89.08, 97.02 and $95.03 \%$

$5 \mathrm{ng} / \mathrm{mL}$

QC \% nominal. cone., $100.67 \%$

QC coefficient of variation, $4.48 \%$

Mean \% change, $-9.71,-7.40$ and $-2.68 \%$

Mean \% change after 24 hours, $-9.34,-9.03$ and $-1.77 \%$

Mean $\%$ change after 52 days, $-11.12,-7.09$ and $-3.05 \%$ QC \% nominal conc., 103.66, 95.75 and $95.61 \%$

[20]. Patricia, Z.; Rita, C.; Maria, A. R.; Maria, T. P. J. Pharmaceut. Biomed. Anal. 2002, 27, 833-836.

[21]. Tayebeh, G.; Farzad, K.; Seyed, A. M. Iranian J. Pharm. Res. 2013, 12, 57-63.

[22]. Hashemi, M. S. H.; Kobarfard, F.; Husain, S. W.; Tehrani, M. S.; Abroomand, A. P.; Ahmadkhanihac, R.; Mehdizadeh, A. Iranian I. Pharm. Res. 2012, 11, 59-67.

[23]. Fei, L.; Yu, X.; Jinchang, H.; Shu, G.; Qingxiang, G. Biomed Chromatogr. 2007, 21(12), 1272-1278.

[24]. Xue-Min, Z.; Jie, L.; Juan, G.; Quan-Sheng, Y.; Wen-Yan, W. Pharmazie 2007, 62, 255-257.

[25]. Gobela, A.; Thomsena, A.; McArdella, C.; Aldera, A.; Gigera, W.; Theibb, N.; Lofflerb, D.; Ternes, T. J. Chromatog. A 2005, 1085(2), 179-189.

[26]. Chena, B.; Liangb, Y.; Chenc, X.; Liua, S.; Denga, F.; Zhoua, P. J. Pharm. Biomed. Anal. 2006, 42(4), 480-487.

[27]. Xu, F.; Zhang, Z.; Bian, Z.; Tian, Y.; Jiao, H.; Liu, Y. J. Chromatogr. Sci. 2008, 46, 479-484.

[28]. Supattanapong, S.; Konsil, J. Southeast Asian J. Trop. Med. Public Health 2008, 39(6), 979-987.

[29]. Hidy, B. J.; Lewis, J.; Ke, J. Proceedings of $50^{\text {th }}$ ASMS Conference on Mass Spectrometry and Applied Topics, Orlando, Florida, 2002.

[30]. U.S. Department of Health and Human Services, Food and Drug Administration (US FDA). Guidance for Industry, Bioanalytical Method Validation. FDA/CDER/CVM, Federal Register, 2001, Available from: URL: http://www.fda.gov/cder/guidance/4252fnl.pdf 